
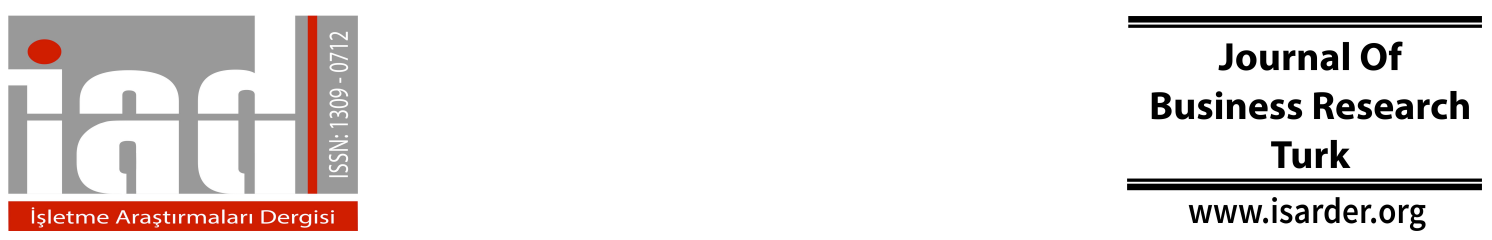

\title{
An Integrated MCDM Model for Occupational Safety Specialist Selection
}

\author{
Zehra KAMIŞLI ÖZTÜRK \\ Anadolu University \\ Faculty of Engineering \\ Eskişehir, Turkey \\ orcid.org/0000-0003-3156-6464 \\ zkamisli@,anadolu.edu.tr
}

\author{
Şura TOPTANCI ${ }^{1}$ \\ Anadolu University \\ Faculty of Engineering \\ Eskişehir, Turkey \\ orcid.org/0000-0002-3612-2478 \\ sura t@anadolu.edu.tr
}

\begin{abstract}
For businesses in the public and private sectors, the selection process of occupational safety specialist is critical since these employees identify and prevent work-related hazards. In the field of human resource management, using an effective and accurate model for the selection of these employees is especially valuable. In this study, the occupational safety specialist problem is considered for a Mutual Health and Safety Unit. The selection is made among five candidates who pass pre-selection process. An integrated multi-criteria decision making model based on Benefits, Opportunities, Costs and Risks (BOCR) criteria has been developed for this study. AHP is used to determine the weights of selection criteria and COPRAS is used to select the most pertinent personnel in correlation the selection criteria. To determine BOCR priorities a five-point scale and for other pairwise comparisons Saaty's 1-9 scale are used. The effectiveness of the proposed model is demonstrated in a real application.
\end{abstract}

Keywords: AHP, COPRAS, multi criteria decision making (MCDM), occupational safety specialist, personnel selection

\section{Introduction}

Occupational accidents are a great concern for businesses since they unexpectedly and unavoidably cause fatal and non-fatal injuries in the workplace. Occupational health and safety (OHS) regulations are in place to protect the health, safety and welfare of employees and other staff at the workplace. OHS regulations are utilized to mitigate the possibility of occupational accidents. Occupational safety specialists implement OHS regulations to identify, prevent and inspect health and safety hazards.

Effective occupational safety specialists inform and prepare employees to ensure the successful implementation of health and safety hazard protocols. This, ideally, translates into maximum cost effectiveness and a continued safety management process. As such, ensuring a good fit in the selection of effective occupational hazard specialists translates into the aforementioned benefits for the employing companies.

\footnotetext{
${ }^{1}$ Corresponding Author
} 
The selection of occupational safety specialist is mainly a personnel selection problem. In the selection of personnel, human resource managers want to match the individual with pre-defined qualifications to make the best fit for a specific job description. Changes in work, regulations, society, marketing and organizations affect the personnel selection process (Dursun and Karsak, 2010).

The process may consist of three fundamental phases: i-) identification of criteria for personnel selection, ii-) pre-selection of staff and iii-) final selection of staff for the right position. Firstly, the specific requirements of the job position and the criteria (preselection and selection) for personnel selection are identified. Secondly, personnel alternatives are pre-selected through the pre-selection criteria to make a shortlist since there may be many applicants for the same position. Finally, pre-selected personnel alternatives are selected using the main selection criteria.

Due to the need to consider many criteria in the pre-selection and selection phases, personnel selection is a multi-criteria decision making (MCDM) problem. In literature, there are various methods and criteria used to select the appropriate personnel for the right position. One of the primary studies on the topic found in existing literature, Gargano et al. (1991), proposes a genetic algorithm and an artificial neural network to solve personnel selection problems in the finance sector.

Additionally, Miller and Feinzig (1993) and Liang and Wang (1994) used fuzzy set theory to handle uncertainty efficiently in solving personnel selection problems. Moreover, Capaldo and Zollo (2001) used fuzzy set theory to select the best personnel in a very large Italian company. In another attempt, Karsak (2000) proposed fuzzy multi objective programming to address personnel selection problems. Apart from these models, MCDM models, such as the Analytic Hierarchy Process (AHP), Analytic Network Process (ANP), Additive Ratio Assessment (ARAS), Step-wise Weight Assessment Ratio Analysis (SWARA), Technique for Order Preference by Similarity to Ideal Solution (TOPSIS), Decision-Making Trial and Evaluation Laboratory (DEMATEL) and the fuzziness of these models were used to select preferred personnel. For example, Gibney and Shang (2007) proposed AHP to select the right individual for a position as dean at a university and Karabašević et al. (2015) used SWARA and ARAS for the selection of a sales manager in a telecommunication industry.

Moreover, some of the studies integrated AHP with fuzzy set theory to solve personnel selection problems. For instance, Dağdeviren (2007) proposed fuzzy AHP to select personnel for a position in the department of import-export at a business. Moreover, Güngör et al. (2009) proposed fuzzy AHP including the weighted goal method to solve personnel selection problems and to measure the viability of fuzzy AHP.

Even though AHP and fuzzy AHP enable decision makers to obtain efficient results in solving of personnel selection problems, these methods are not sufficient to handle preferable and non-preferable criteria separately. In both personnel selection problems and other multi criteria decision making problems, two types of criteria are considered; preferable and non-preferable. Preferable criteria should be considered to the largest extent possible and non-preferable criteria should be the counterbalance. Some of the studies proposed TOPSIS and VIKOR to take into account both preferable and non-preferable criteria. For instance, Celik et al. (2009) proposed an integrated model including fuzzy AHP and fuzzy TOPSIS to select academic staff for a university. 
In another attempt, Dursun and Karsak (2010) integrated a dual fuzzy linguistic representation model, ordered weighted averaging (OWA) and TOPSIS to solve personnel selection problem. Moreover, Klemenis and Askounis (2010) used fuzzy TOPSIS to select the best personnel for an information technology company. Additionally, Vatansever and Oncel (2014) proposed fuzzy AHP and fuzzy TOPSIS and Akın (2016) used fuzzy TOPSIS to select a research assistant for a university. Also, the VIKOR method was used to solve personnel selection problems in literature. As an example for using VIKOR, El-Santawy and El-Dean (2012) used VIKOR to select preferred personnel. On the other hand, Yildiz and Deveci (2013) proposed fuzzy VIKOR to address personnel selection problems.

ANP was also used to solve personnel selection problems. For instance, Lin (2010) proposed ANP and fuzzy data envelopment analysis to select preferred personnel. In another attempt, Aksakal and Dağdeviren (2010) used an integrated model including DEMATEL and ANP to select the best personnel. Additionally, Kabak et al. (2012) integrated fuzzy ANP, fuzzy TOPSIS and fuzzy ELECTRE to select sniper alternatives.

Even though MCDM methods were used to solve personnel selection problems for different sectors, there are no studies in the literature related to the selection of occupational safety specialists for public and private businesses. Therefore, this study proposes a new and systematic model including the AHP, BOCR and COPRAS methods to select occupational safety specialist for a real company in Turkey.

The remainder of this paper is structured as follows: the BOCR, AHP and COPRAS methods will be explained in section 2. In section 3, the application of the proposed model will be presented. Finally, the conclusion will be presented in section 4 .

\section{Methodology}

\subsection{The Analytic Hierarchy Process (AHP) and BOCR}

The AHP was developed by Saaty (1980) and has been identified as an important approach to multi criteria decision making problems of selection and prioritization. The AHP is a theory that depends on the values and judgements of individuals and groups. It is used to derive ratio scales from both discrete and continuous paired comparisons in multilevel hierarchic structures. In its general form, the AHP is a nonlinear framework for carrying out both deductive and inductive thinking (Saaty, 2001).

The first step of AHP is the definition of decision problems and the determination of its objective. Then, the decision criteria are defined in the form of a hierarchy. To make pair-wise comparisons, the comparison matrices of criteria and decision alternatives are constructed. By making the comparisons, the weights (importance) of each criterion are obtained. In the final step, by hierarchical synthesis, the weights (priorities) of the alternatives are obtained. The methodology of the AHP can be explained in following steps:

Step 1: The problem is decomposed into a hierarchy of goal, criteria, sub-criteria and alternatives.

Step 2: In order to compute the weights for the different criteria, the AHP starts by creating a pairwise comparison matrix A. Data are collected from experts or 
decision-makers corresponding to the hierarchic structure. The pairwise comparisons are made based on the fundamental scale of Saaty given in Table 1.

After comparisons the matrix A, which is comparison matrix, can be written as:

$$
A=\left[a_{i j}\right]_{n \times n}
$$

In this matrix, if $i$ equals $\mathrm{j}$ to, $a_{i j}$ is one. Additionally, $a_{i j}^{-1}$ can be written as below:

$$
a_{i j}^{-1}=\frac{1}{a_{i j}}
$$

Step 3: Each element of the matrix will be divided into the sums of each column to obtain $B_{i}$ a matrix:

$$
B_{i}=\left[b_{i j}\right]_{n \times 1}
$$

The elements of this matrix $\left(b_{i j}\right)$ can be written as follows:

$$
b_{i j}=\frac{a_{i j}}{\sum_{i=1}^{n} a_{i j}}
$$

Step 4: The matrix $C$ consists of the each $B_{i}$ column vectors.

Step 5: Each element of the priority vector $\left(w_{j}\right)$, that is, the weight of $\mathrm{jth}$ criterion is obtained from the matrix $\mathrm{C}$ by the following equation:

$$
w_{j}=\frac{\sum_{j=1}^{n} c_{i j}}{n}
$$

Step 6: Finally, the consistency index of the comparison matrix can be calculated as:

$$
\begin{gathered}
C I=\frac{\left(\lambda_{\max }-n\right)}{(n-1)} \\
\mathrm{CR}=\mathrm{CI} / \mathrm{RI}
\end{gathered}
$$

In Equation 6, $\lambda_{\max }$ is the largest eigenvalue, $\mathrm{CI}$ is the consistency index, CR is the consistency ratio and RI is the random index. If the consistency ratio is less than 0.1 , comparison matrix is accepted; otherwise, a new comparison matrix is structured.

Table 1. The Fundamental Scale

\begin{tabular}{|c|c|}
\hline Importance Values & Value Definitions \\
\hline 1 & Equally important \\
\hline 3 & Somewhat important \\
\hline 5 & More important \\
\hline 7 & Much more important \\
\hline 9 & Extremely important \\
\hline $2,4,6,8$ & Intermediate values \\
\hline
\end{tabular}

Any decision has several favourable and unfavourable concerns to consider. Some of these are readily determinable; others are less certain and have a likelihood of not materializing. The favourable, readily determinable parameters are called Benefits while the unfavourable parameters are called Costs. The uncertain concerns of a decision are the positive Opportunities that the decision might create and the negative Risks that it 
can entail. Each of these four concerns utilizes a separate structure to reach the decision, beginning with a benefits control structure and the network of interdependencies that belongs under each benefit control criterion, and ending with a risks control structure. The four concerns collectively as BOCR, have used the initials of the positive ones (benefits and opportunities) before the initials of the negative ones (costs and risks). Each of these concerns contributes to merit a decision and must be evaluated (rated) individually on a set of (prioritized) criteria that is used to rate any other decision (Saaty, 2001). In this study, we assume that all BOCR merits do not have same importance. As such, some strategic criteria are determined in the previous level of the BOCR criteria level. Finally, the sub-criteria are determined under the level of the BOCR criteria.

As Saaty said, the size of pairwise comparison matrix should be at most 9x9 size in terms of consistency. Therefore, if the number of candidates to be evaluated under this study is greater than 9, the AHP method alone will not be sufficient for evaluation. From this point, the evaluation criteria are determined by AHP and the selection of candidates is made by COPRAS which has no size limitation. In following section, the COPRAS method is explained in detail.

\subsection{The Complex Proportional Assessment (COPRAS)}

After obtaining weights of criteria in AHP, COPRAS (Zavadskas ve Kaklauskas, 1996) will be used to rank personnel alternatives. The COPRAS method determines direct and proportional dependence of significance and priority of alternatives with regard to the criteria (Ulutas et al., 2016). The steps of this method can be written as:

Step 1: The decision matrix (D) for personnel selection can be structured as:

$$
D=\left[d_{l j}\right]=\begin{gathered}
P_{1} \\
P_{2} \\
\ldots \\
\ldots \\
P_{l} \\
\ldots \\
\ldots \\
P_{m}
\end{gathered}\left[\begin{array}{cccccc}
x_{11} & x_{12} & \ldots & x_{1 j} & \ldots & x_{1 n} \\
x_{21} & x_{22} & \ldots & x_{2 j} & \ldots & x_{2 n} \\
\ldots & \ldots & \ldots & \ldots & \ldots & \ldots \\
\ldots & \ldots & \ldots & \ldots & \ldots & \ldots \\
x_{l 1} & x_{l 2} & \ldots & x_{l j} & \ldots & x_{i n} \\
\ldots & \ldots & \ldots & \ldots & \ldots & \ldots \\
x_{m 1} & x_{m 2} & \ldots & x_{m j} & \ldots & x_{m n}
\end{array}\right]
$$

where, $n$ is the number of criteria and $m$ is the number of alternatives.

Step 2: In equation $8, x_{l j}$ is the score of $l^{\text {th }}$ individual with respect to $j^{\text {th }}$ criterion. Each element of decision matrix can be normalised as below:

$$
x_{l j}^{*}=\frac{x_{l j}}{\sum_{l=1}^{m} x_{l j}} \quad j=1,2, \ldots . n
$$

where, $j$ refers to the criterion, $x_{l j}^{*}$ denotes the normalized value of $x_{l j}$ and $l$ refers to the individual alternative.

Step 3: Normalised scores are multiplied by the weights of criteria to obtain a weighted normalised matrix. The weighted normalised matrix can be calculated as:

$$
D^{\prime}=\left[d_{l j}^{\prime}\right]_{m \times n}=x_{l j}^{*} \times w_{j}
$$

In this study $w_{j}$ is obtained from AHP from equation (5). 
Step 4: In weighted normalised matrix, the values assigned to preferable criteria (Benefits and Opportunities) can be summed up by using equation 11 for each individual. Additionally, the values assigned to non-preferable criteria (Cost and Risk) can be summed up by using equation 12 for each individual.

$$
\begin{array}{cl}
S_{l}^{+}=\sum_{j=1}^{o} d_{l j}^{\prime} & \text { for preferable criteria } \\
S_{l}^{-}=\sum_{j=o+1}^{n} d_{l j}^{\prime} & \text { for non-preferable criteria }
\end{array}
$$

where, $o$ is the total number of preferable criteria, $S_{l}^{+}$is the sums of preferable criteria and $S_{l}^{-}$is the sums of non- preferable criteria.

Step 5: After obtaining the sum of values for preferable and non-preferable criteria for each individual, the relative weight $\left(Q_{l}\right)$ of $l^{\text {th }}$ individual can be calculated as:

$$
Q_{l}=S_{l}^{+}+\frac{\sum_{l=1}^{m} s_{l}^{-}}{\left(S_{l}^{-} * \sum_{l=1}^{m} \frac{1}{S_{l}^{-}}\right)}
$$

Step 6: After obtaining $Q_{l}$ of $l^{\text {th }}$ individual, the overall performance score $\left(U_{l}\right)$ of $l^{\text {th }}$ individual can be calculated as:

$$
U_{l}=\left(\frac{Q_{l}}{Q_{\max }}\right)
$$

The next section will present the application of the proposed model.

\section{Application of Proposed Integrated Model to Occupational Safety Specialist}

In this study, we propose an integrated MCDM model that consists of AHP and COPRAS methods with BOCR analysis. The model was implemented in the company "X Mutual Health and Safety Unit" that was established to provide occupational health and safety services to the workplaces in Turkey. The selection of an occupational safety specialist in the company was made from among five alternative candidates that passed the expert group's pre-selection application process and then took part in an interview and a week-long orientation.

A total of 25 criteria were determined after reviewing the literature on personnel selection and the published legislation/regulations related to occupational safety expertise in the official gazette of the Republic of Turkey (2012) together with the expert opinions of the company X. Alternatives were subjected to the preliminary evaluation within the framework of the first five criteria listed in Table 2. The five alternatives that achieved to fulfil the pre-selection requirements were considered eligible for evaluation by 20 other specified criteria in the process of interviewing and orientation program.

Just as with the calculation phases described in section 2, AHP-COPRAS model with BOCR analysis was applied to select the occupational safety specialist among five candidates. 
Table 2. Pre-selection Criteria

The Criteria Used In The Preliminary Evaluation Process

1. Certificate of occupational safety expertise (The General Directorate of Occupational Health and Safety of the Ministry of Labour and Social Security Approved).

2. Type of graduated program.

3. Having a driver's license and no restriction to travel.

4. Being exempted from military service (for male candidates).

5. Medical report indicating the suitability to work.

\subsection{Assigning Weights to Selection Criteria}

The purpose of the proposed model was put at the top of the hierarchy of the AHP model as "The Selection of The Best/Most Appropriate Occupational Safety Specialist". Three different strategic criteria including economic benefits, compliance with laws and assessment by the company were used to determine the BOCR priorities.

1) Economic Benefits: Providing reduction to the number and cost of occupational accidents, the solution of the problem will help to prevent loss of nation and company.

2) Compliance with Laws: Solving this problem will ensure that the company apply the occupational health and safety legislation more effectively and accurately against the background of possible sanctions, large fines and other risks.

3)Assessment by The Company: Ensuring that the company take the necessary precautions against all types of risks by an effective safety management, the solution of this problem will help to provide a safer work environment and the safety of employees, the company and production. 


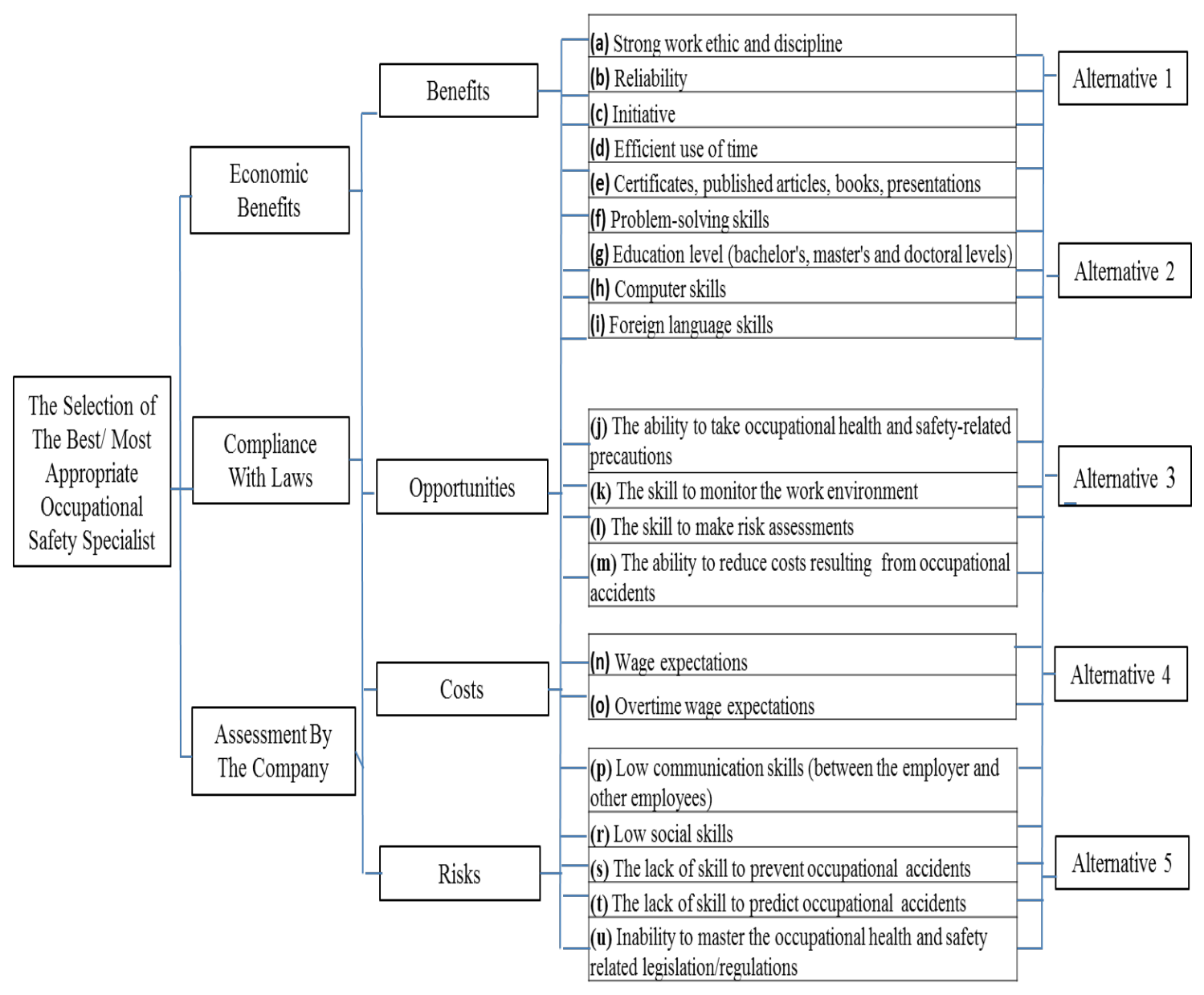

Figure 1. A Hierarchy for Occupational Safety Specialist Selection Problem

20 criteria for personnel selection were defined under the BOCR merits. The hierarchical structure of the selection issue of the most appropriate safety specialist with strategic criteria, BOCR merits and sub-criteria are given in Figure 1. Selection diagrams are oriented from left to right.

In the first phase of the proposed model, pairwise comparisons of strategic criteria, BOCR merits and sub-criteria were made. A questionnaire survey was prepared to perform the pairwise comparisons. These surveys were filled in by two experts who were responsible for recruitment in Company X. In survey questions, to determine the BOCR priorities a five point rating scale (very low, low, medium, high, very high) and for other pairwise comparisons Saaty's 1-9 scale were used. The consensus of the two experts was taken for questions regarding the BOCR priorities, and the data which form the other pairwise comparisons was identified based on the geometric mean of the responses of the two experts to the questions.

Expert Choice software was used to calculate the priorities of strategic criteria and sub-criteria of BOCR merits in this paper. The comparison matrix and weights of the strategic criteria with BOCR priorities are shown in Tables 3-4. 
Z. Kamışlı Öztürk - Ş. Toptancı 9/4 (2017) 419-435

Table 3. Pairwise Comparisons Matrix of Strategic Criteria

\begin{tabular}{lccc}
\hline & $\begin{array}{c}\text { Economic } \\
\text { Benefits }\end{array}$ & $\begin{array}{c}\text { Compliance } \\
\text { With Laws }\end{array}$ & $\begin{array}{c}\text { Assessment By } \\
\text { The Company }\end{array}$ \\
\hline Economic Benefits & - & 1 & 1,41 \\
\hline Compliance With Laws & 1 & - & 2,45 \\
\hline $\begin{array}{l}\text { Assessment By The } \\
\text { Company }\end{array}$ & 0,709 & 0,408 & - \\
\hline Cons &
\end{tabular}

Consistency Ratio (C.R.) $=0,03$.

Table 4. Weights of Strategic Criteria with BOCR Priorities

\begin{tabular}{|c|c|c|c|c|c|}
\hline & $\begin{array}{l}\text { Economic } \\
\text { Benefits } \\
(\mathbf{0 , 3 5 8 )}\end{array}$ & $\begin{array}{c}\text { Compliance } \\
\text { With Laws } \\
(\mathbf{0 , 4 3 1 )}\end{array}$ & $\begin{array}{l}\text { Assessment } \\
\text { By The } \\
\text { Company } \\
(\mathbf{0 , 2 1 1 )}\end{array}$ & Priorities & $\begin{array}{l}\text { Normalized } \\
\text { Priorities }\end{array}$ \\
\hline Benefits & Very High & Very High & Very High & 0,42 & 0,343 \\
\hline Opportunities & High & High & Very High & 0,294 & 0,240 \\
\hline Costs & High & Medium & High & 0,217 & 0,177 \\
\hline Risks & Medium & Very High & High & 0,293 & 0,239 \\
\hline
\end{tabular}

Rating scale: Very High: 0.42, High: 0.26, Medium: 0.16, Low: 0.10, Very Low: 0.06.

Tables 5-8 indicate the weights of sub-criteria under BOCR merits and consistency ratios. Since the consistency ratio of the comparison matrices is less than 0.1 , the comparisons can be considered consistent.

Table 5. The Pairwise Comparisons Matrix For The Sub-criteria of Benefits Merit

\begin{tabular}{cccccccccc}
\hline Benefits & $\mathrm{a}$ & $\mathrm{b}$ & $\mathrm{c}$ & $\mathrm{d}$ & $\mathrm{e}$ & $\mathrm{f}$ & $\mathrm{g}$ & $\mathrm{h}$ & $\mathrm{i}$ \\
\hline $\mathrm{a}$ & - & 0,258 & 3,46 & 2,45 & 2 & 1 & 1,41 & 1 & 2,45 \\
\hline $\mathrm{b}$ & 3,87 & - & 4,24 & 2,45 & 2,45 & 1,41 & 2,45 & 2 & 2,45 \\
\hline $\mathrm{c}$ & 0,289 & 0,236 & - & 0,5 & 0,709 & 0,289 & 1 & 1,41 & 2 \\
\hline $\mathrm{d}$ & 0,408 & 0,408 & 2 & - & 3 & 0,25 & 1 & 1,41 & 2,45 \\
\hline $\mathrm{e}$ & 0,500 & 0,408 & 1,41 & 0,333 & - & 0,353 & 1,41 & 2,45 & 2 \\
\hline $\mathrm{f}$ & 1 & 0,709 & 3,46 & 4 & 2,83 & - & 2,83 & 2,83 & 3,87 \\
\hline $\mathrm{g}$ & 0,709 & 0,408 & 1 & 1 & 0,709 & 0,353 & - & 0,578 & 1,41 \\
\hline $\mathrm{h}$ & 1 & 0,500 & 0,709 & 0,709 & 0,408 & 0,353 & 1,73 & - & 2,83 \\
\hline $\mathrm{i}$ & 0,408 & 0,408 & 0,5 & 0,408 & 0,5 & 0,258 & 0,709 & 0,353 & - \\
\hline
\end{tabular}

C.R. $=0,06$. 
Table 6. The Pairwise Comparisons Matrix For The Sub-criteria of Opportunities Merit

\begin{tabular}{ccccc}
\hline Opportunities & $\mathrm{j}$ & $\mathrm{k}$ & $\mathrm{l}$ & $\mathrm{m}$ \\
\hline $\mathrm{j}$ & - & 1,73 & 1 & 2,45 \\
\hline $\mathrm{k}$ & 0,578 & - & 1 & 3,46 \\
\hline $\mathrm{l}$ & 1 & 1 & - & 3,46 \\
\hline $\mathrm{m}$ & 0,408 & 0,289 & 0,289 & - \\
\hline
\end{tabular}

C.R. $=0,03$.

Please note that, the values according to each pairwise comparison are not integers since the two experts' separate judgements were merged by calculating the geometric mean of them.

Table 7. The Pairwise Comparisons Matrix For The Sub-criteria of Costs Merit

\begin{tabular}{ccc}
\hline Costs & $\mathrm{n}$ & $\mathrm{o}$ \\
$\mathrm{n}$ & - & 5,92 \\
\hline $\mathrm{o}$ & 0,169 & - \\
\hline
\end{tabular}

C.R. $=0,00$.

Table 8. The Pairwise Comparisons Matrix For The Sub-criteria of Risks Merit

\begin{tabular}{cccccc}
\hline Risks & $\mathrm{p}$ & $\mathrm{r}$ & $\mathrm{s}$ & $\mathrm{t}$ & $\mathrm{u}$ \\
\hline $\mathrm{p}$ & - & 3,46 & 0,289 & 0,236 & 0,154 \\
\hline $\mathrm{r}$ & 0,289 & - & 0,126 & 0,126 & 0,136 \\
\hline $\mathrm{s}$ & 3,46 & 7,94 & - & 0,578 & 1 \\
\hline $\mathrm{t}$ & 4,24 & 7,94 & 1,73 & - & 1,73 \\
\hline $\mathrm{u}$ & 6,48 & 7,35 & 1 & 0,578 & - \\
\hline
\end{tabular}

C.R. $=0,03$.

Table 9. The Weights of the Sub-criteria and Global Weights of Criteria

\begin{tabular}{clcc}
\hline BOCR & \multicolumn{1}{c}{ Sub-criteria } & $\begin{array}{c}\text { Weights of } \\
\text { Sub-criteria }\end{array}$ & $\begin{array}{c}\text { Global } \\
\text { Weights of } \\
\text { Criteria }\end{array}$ \\
\hline & (a) Strong work ethic and discipline & 0,135 & 0,046 \\
& (b) Reliability & 0,225 & 0,077 \\
& (c) Initiative & 0,061 & 0,021 \\
& (d) Efficient use of time & 0,1 & 0,034 \\
Benefits & (e) Certificates, published & 0,085 & 0,029 \\
$(0,343)$ & articles, books, presentations & & \\
& (f) Problem-solving skills & 0,2 & 0,069 \\
& (g) Education level (bachelor's, & 0,068 & 0,023 \\
& master's and doctoral levels) & & 0,028 \\
& (h) Computer skills & 0,082 & 0,015 \\
\hline (i) Foreign language skills & 0,045 & 0,079 \\
Opportunities & (j) The ability to take occupational & 0,328 &
\end{tabular}


(k) The skill to monitor the work $\quad 0,27 \quad 0,069$ environment

(l) The skill to make risk $\quad 0,304 \quad 0,073$ assessments

(m) The ability to reduce costs $\quad 0,097 \quad 0,023$ resulting from occupational accidents

\begin{tabular}{clll}
\hline Costs & (n) Wage expectations & 0,855 & 0,151 \\
$(0,177)$ & (o) Overtime wage expectations & 0,145 & 0,026 \\
\hline & $\begin{array}{l}\text { (p) Low communication skills } \\
\text { (between the employer and other }\end{array}$ & 0,076 & 0,018 \\
& $\begin{array}{l}\text { employees) } \\
\text { (r) Low social skills }\end{array}$ & 0,033 & 0,008 \\
& $\begin{array}{l}\text { (s) The lack of skill to prevent } \\
\text { Risks }\end{array}$ & 0,245 & 0,059 \\
$(0,239)$ & $\begin{array}{l}\text { occupational accidents } \\
\text { (t) The lack of skill to predict }\end{array}$ & 0,361 & 0,086 \\
& $\begin{array}{l}\text { occupational accidents } \\
\text { (u) Inability to master the }\end{array}$ & 0,285 & 0,068 \\
& $\begin{array}{l}\text { occupational health and safety } \\
\text { related legislation/regulations }\end{array}$ & & \\
\hline
\end{tabular}

The weights of BOCR merits and sub-criteria obtained from comparisons are given in Table 9. The Benefits merit has the highest weight with $34.32 \%$. At the calculation phase of general weights of criteria, the weights of BOCR and sub-criteria are multiplied.

\subsection{The Ranking of Personnel Alternatives}

After obtaining the global weights of criteria used for the selection of the most appropriate occupational safety specialist, the COPRAS method was used to rank 5 individual alternatives who passed the pre-selection phase. Another questionnaire survey was prepared to assess alternatives for 20 criteria in this step. COPRAS decision matrix data was derived from the score values listed in Table 10 by taking the geometric mean of the experts' responses to the survey.

Table 10. Score Values

\begin{tabular}{|c|c|}
\hline Score Values & Value Definitions \\
\hline 1 & Extremely Weak \\
\hline 2 & Very Weak \\
\hline 3 & Weak \\
\hline 4 & Lower \\
\hline 5 & Medium \\
\hline 6 & Over Medium \\
\hline 7 & Good \\
\hline 8 & Very Good \\
\hline 9 & Extremely Good \\
\hline
\end{tabular}

Table 11 gives the COPRAS decision matrix. It contains the BOCR evaluation criteria and five alternatives. 
Z. Kamışlı Öztürk - Ş. Toptanc1 9/4 (2017) 419-435

Table 11. Decision Matrix

\begin{tabular}{|c|c|c|c|c|c|c|}
\hline \multirow{2}{*}{ BOCR } & \multirow{2}{*}{ Sub- Criteria } & \multicolumn{5}{|c|}{ Alternatives } \\
\hline & & Individual 1 & Individual 2 & Individual 3 & Individual 4 & Individual 5 \\
\hline \multirow{9}{*}{ Benefits } & $\mathrm{a}$ & 6,00 & 6,48 & 6,93 & 7,48 & 7,94 \\
\hline & $\mathrm{b}$ & 5,48 & 7,48 & 6,48 & 6,93 & 7,48 \\
\hline & $\mathrm{c}$ & 6,48 & 7,48 & 5,48 & 7,00 & 5,92 \\
\hline & d & 7,94 & 6,93 & 5,92 & 6,93 & 7,48 \\
\hline & $\mathrm{e}$ & 7,94 & 7,48 & 9,00 & 7,48 & 7,00 \\
\hline & $\mathrm{f}$ & 6,48 & 7,48 & 5,92 & 7,48 & 7,48 \\
\hline & g & 6,93 & 6,48 & 5,00 & 3,46 & 5,48 \\
\hline & $\mathrm{h}$ & 6,48 & 7,48 & 3,87 & 4,90 & 5,48 \\
\hline & $\mathrm{i}$ & 7,48 & 6,48 & 6,93 & 5,00 & 4,90 \\
\hline \multirow{4}{*}{ Opportunities } & $\mathrm{j}$ & 6,48 & 5,48 & 7,48 & 6,48 & 6,93 \\
\hline & $\mathrm{k}$ & 6,93 & 6,93 & 7,48 & 7,94 & 7,48 \\
\hline & 1 & 5,92 & 6,93 & 7,94 & 6,48 & 3,46 \\
\hline & $\mathrm{m}$ & 6,48 & 6,93 & 5,92 & 6,93 & 6,48 \\
\hline \multirow{2}{*}{ Costs } & $\mathrm{n}$ & 6,48 & 7,48 & 6,93 & 7,00 & 6,48 \\
\hline & o & 5,92 & 6,48 & 7,48 & 6,48 & 6,48 \\
\hline \multirow{5}{*}{ Risks } & $\mathrm{p}$ & 5,92 & 6,48 & 7,00 & 6,93 & 7,48 \\
\hline & $\mathrm{r}$ & 6,48 & 7,48 & 7,00 & 7,00 & 6,93 \\
\hline & $\mathrm{s}$ & 6,48 & 7,48 & 6,48 & 7,35 & 5,48 \\
\hline & $\mathrm{t}$ & 7,48 & 4,47 & 6,48 & 6,93 & 5,92 \\
\hline & $\mathrm{u}$ & 6,48 & 5,92 & 4,9 & 7,48 & 6,93 \\
\hline
\end{tabular}

Table 12. Standardized (Normalized) Decision Matrix

\begin{tabular}{|c|c|c|c|c|c|c|}
\hline \multirow{2}{*}{ BOCR } & \multirow{2}{*}{ Sub-criteria } & \multicolumn{5}{|c|}{ Alternatives } \\
\hline & & Individual 1 & Individual 2 & Individual 3 & Individual 4 & Individual 5 \\
\hline \multirow{9}{*}{ Benefits } & $\mathrm{a}$ & 0,172 & 0,186 & 0,199 & 0,215 & 0,228 \\
\hline & $\mathrm{b}$ & 0,162 & 0,221 & 0,191 & 0,205 & 0,221 \\
\hline & $\mathrm{c}$ & 0,200 & 0,231 & 0,169 & 0,216 & 0,183 \\
\hline & $d$ & 0,226 & 0,197 & 0,168 & 0,197 & 0,213 \\
\hline & e & 0,204 & 0,192 & 0,231 & 0,192 & 0,180 \\
\hline & $\mathrm{f}$ & 0,186 & 0,215 & 0,170 & 0,215 & 0,215 \\
\hline & g & 0,253 & 0,237 & 0,183 & 0,127 & 0,200 \\
\hline & $\mathrm{h}$ & 0,230 & 0,265 & 0,137 & 0,174 & 0,194 \\
\hline & $\mathrm{i}$ & 0,243 & 0,211 & 0,225 & 0,162 & 0,159 \\
\hline \multirow{4}{*}{ Opportunities } & $\mathrm{j}$ & 0,197 & 0,167 & 0,228 & 0,197 & 0,211 \\
\hline & $\mathrm{k}$ & 0,189 & 0,189 & 0,204 & 0,216 & 0,204 \\
\hline & 1 & 0,193 & 0,226 & 0,258 & 0,211 & 0,113 \\
\hline & $\mathrm{m}$ & 0,198 & 0,212 & 0,181 & 0,212 & 0,198 \\
\hline \multirow{2}{*}{ Costs } & $\mathrm{n}$ & 0,189 & 0,218 & 0,202 & 0,204 & 0,189 \\
\hline & o & 0,180 & 0,197 & 0,228 & 0,197 & 0,197 \\
\hline \multirow{5}{*}{ Risks } & $\mathrm{p}$ & 0,175 & 0,192 & 0,207 & 0,205 & 0,221 \\
\hline & $\mathrm{r}$ & 0,186 & 0,215 & 0,201 & 0,201 & 0,199 \\
\hline & s & 0,195 & 0,225 & 0,195 & 0,221 & 0,165 \\
\hline & $\mathrm{t}$ & 0,239 & 0,143 & 0,207 & 0,222 & 0,189 \\
\hline & $\mathrm{u}$ & 0,204 & 0,187 & 0,155 & 0,236 & 0,219 \\
\hline
\end{tabular}


Z. Kamışlı Öztürk - Ş. Toptanc1 9/4 (2017) 419-435

Table 13. Weighted Standardized (Normalized) Decision Matrix

\begin{tabular}{c|c|ccccc}
\hline \multirow{2}{*}{ BOCR } & \multirow{2}{*}{ Sub-criteria } & \multicolumn{5}{c}{ Alternatives } \\
\cline { 3 - 6 } & & Individual 1 & Individual 2 & Individual 3 & Individual 4 & Individual 5 \\
\hline \multirow{5}{*}{ Benefits } & $\mathrm{a}$ & 0,008 & 0,009 & 0,009 & 0,010 & 0,011 \\
& $\mathrm{~b}$ & 0,013 & 0,017 & 0,015 & 0,016 & 0,017 \\
& $\mathrm{c}$ & 0,004 & 0,005 & 0,004 & 0,005 & 0,004 \\
& $\mathrm{~d}$ & 0,008 & 0,007 & 0,006 & 0,007 & 0,007 \\
& $\mathrm{e}$ & 0,006 & 0,006 & 0,007 & 0,006 & 0,005 \\
& $\mathrm{f}$ & 0,013 & 0,015 & 0,012 & 0,015 & 0,015 \\
& $\mathrm{~g}$ & 0,006 & 0,006 & 0,004 & 0,003 & 0,005 \\
& $\mathrm{~h}$ & 0,007 & 0,008 & 0,004 & 0,005 & 0,006 \\
\multirow{5}{*}{ Opportunities } & $\mathrm{i}$ & 0,004 & 0,003 & 0,004 & 0,003 & 0,003 \\
\hline \multirow{2}{*}{ Costs } & $\mathrm{j}$ & 0,016 & 0,013 & 0,018 & 0,016 & 0,017 \\
& $\mathrm{k}$ & 0,012 & 0,012 & 0,013 & 0,014 & 0,013 \\
& $\mathrm{l}$ & 0,014 & 0,017 & 0,019 & 0,015 & 0,008 \\
& $\mathrm{~m}$ & 0,005 & 0,005 & 0,004 & 0,005 & 0,005 \\
\hline \multirow{6}{*}{ Risks } & $\mathrm{n}$ & 0,029 & 0,033 & 0,031 & 0,031 & 0,029 \\
& $\mathrm{o}$ & 0,005 & 0,005 & 0,006 & 0,005 & 0,005 \\
\hline & $\mathrm{p}$ & 0,003 & 0,004 & 0,004 & 0,004 & 0,004 \\
& $\mathrm{r}$ & 0,002 & 0,002 & 0,002 & 0,002 & 0,002 \\
& $\mathrm{~s}$ & 0,011 & 0,013 & 0,011 & 0,013 & 0,010 \\
& $\mathrm{t}$ & 0,021 & 0,012 & 0,018 & 0,019 & 0,016 \\
& $\mathrm{u}$ & 0,014 & 0,013 & 0,011 & 0,016 & 0,015 \\
\hline
\end{tabular}

The weights in the decision matrix are normalized in Table 12. The global weights of criteria are acquired from the AHP and is multiplied with the weighted, normalized decision matrix and entered into table 13.

For each alternative, the sums of the weighted normalized decision matrix values are calculated from preferable criteria (Benefits and Opportunities) and non-preferable criteria (Costs and Risks). Proximity importance values and performance values are calculated after these operations are shown in Table 14.

Table 14. Separation Measures $\left(S_{l}^{+}, S_{l}^{-}\right)$, Proximity Importance Values $\left(Q_{l}\right)$ and Performance Values $\left(U_{l}\right)$

\begin{tabular}{|c|c|c|c|c|c|}
\hline Alternatives & $S_{l}^{+}$ & $S_{l}^{-}$ & $Q_{l}$ & $U_{l}$ & Ranking \\
\hline Individual 1 & 0,114 & 0,084 & 0,196 & 0,955 & 4 \\
\hline Individual 2 & 0,121 & 0,082 & 0,206 & 1,000 & 1 \\
\hline Individual 3 & 0,118 & 0,082 & 0,203 & 0,984 & 2 \\
\hline Individual 4 & 0,118 & 0,090 & 0,195 & 0,949 & 5 \\
\hline Individual 5 & 0,114 & 0,080 & 0,201 & 0,975 & 3 \\
\hline
\end{tabular}

According to the ranking result, the priority order of the alternatives can be represented as Individual $2>$ Individual $3>$ Individual $5>$ Individual $1>$ Individual 4. It means that the most well-suited candidate is Individual 2 with $100 \%$ performance degree to be employed as the occupational safety specialist. Additionally, ARAS, TOPSIS and VIKOR methods are used to solve this problem. Comparisons of the proposed model with ARAS, TOPSIS and VIKOR ranking are indicated in Table 15. 
Z. Kamışlı Öztürk - Ş. Toptancı 9/4 (2017) 419-435

Table 15. Comparison of Methods' Ranking

\begin{tabular}{|c|c|c|c|c|}
\hline Methods & $\begin{array}{c}\text { Proposed } \\
\text { Model }\end{array}$ & ARAS & TOPSIS & VIKOR \\
\hline Alternatives & 4 & 4 & 5 & 4 \\
\hline Individual 1 & 1 & 1 & 1 & 5 \\
\hline Individual 2 & 2 & 2 & 2 & 2 \\
\hline Individual 3 & 5 & 5 & 3 & 3 \\
\hline Individual 4 & 3 & 3 & 4 & 1 \\
\hline
\end{tabular}

The results of ARAS are similar with the proposed model, however; the results of TOPSIS and VIKOR are not similar with the proposed model. The ranking of Individual 2 and 3 found by using TOPSIS is similar with the proposed model and other alternatives are different. Moreover, the ranking of Individual 1 and 3 found by using VIKOR is similar with the proposed model. Although TOPSIS and VIKOR provide good outcomes, the required computational time is extremely long. Moreover, these two methods are more complex than COPRAS in solving personnel selection problems. Therefore, it can be said that the proposed model provides efficient results and reduce time-wasting in their calculation.

\section{Conclusion}

The human resources are one of fundamental strategic resources of public and private sectors. The personnel selection plays a significant role in the human resource management and it is an important strategic decision problem for the organizations. The ability to select the right personnel for the right position in human resources management will contribute to the efficiency and effectiveness of the organizations.

As there are many criteria to be considered in solving personnel selection problems, this problem is a multi-criteria decision making problem. The selection process of occupational safety specialists is important for the businesses of the public and private sectors as a well-equipped and qualified occupational safety specialist arranges occupational safety management plans and works effectively and accurately towards preventing occupational accidents, fatalities, injuries and illnesses. As it can be seen in Section 1, although there are many studies on the classical personnel selection there has not yet been a study on the selection of occupational safety specialist.

Each candidate takes the same training to get the certificate of occupational safety specialist. However, they do not have the same qualifications and experience. Moreover, in the process of recruiting, the emphasis placed on the importance priority of the qualifications required for the occupational safety specialist mostly is not taken into account. Therefore, it is thought that a study to be carried out in this subject will determine the right candidate who has knowledge and competence to occupational safety specialist position, contribute to minimize the occupational accidents and establish safe working environments.

This study proposes an integrated model including BOCR, AHP, and COPRAS to solve occupational safety specialist selection problem for the company "X Mutual Health and Safety Unit" and this is the first contribution of this study. Additionally, most of the studies in personnel selection literature do not pre-select personnel alternatives. In this study, personnel alternatives were pre-selected to reduce time 
wasting in calculating the rankings of the candidates and this is the second contribution of this study. If alternative numbers are extremely high, pre-selection becomes an important step of personnel selection. In this study, there were many candidates who applied for the job ad, so pre-selection has become a requirement to optimize the selection of occupational safety specialist.

In this study, decision criteria were primarily determined by decision makers in order to evaluate the candidates and determine the appropriate ones. As Saaty said, the size of pairwise comparison matrix should be at most 9x9 size in terms of consistency. Therefore, if the number of candidates to be evaluated under this study is greater than 9 , the AHP method alone will not be sufficient for evaluation. From this point, the evaluation criteria were determined by AHP and the selection of candidates is made by COPRAS which has no size limitation.

Twenty-five evaluation criteria based on literature and regulations were weighted by AHP and the COPRAS method, that takes into account the weighted evaluation criteria, was used to assess the performance of the five candidates who had passed the preliminary process. In this study, ARAS, TOPSIS and VIKOR methods were also used to make comparison with COPRAS. COPRAS method is based on performance values of the alternatives whereas ARAS method is based on ratio sums of alternatives (Aytaç Adalı and Tuş Işik, 2016). In literature, the results of COPRAS and ARAS methods are same or there is a small difference between them (Aytaç Adalı and Tuş Işık, 2016; Özbek and Erol, 2017). According to the results of this study, the ranking performance of COPRAS and ARAS is the same for occupational safety specialist alternatives and the analysis results are consistent with those obtained in a different selection problem using same methods by Aytaç Adalı and Tuş Işık (2016). In addition, since COPRAS method is easier to understand and requires less mathematical operation than VIKOR and TOPSIS, it is thought that a fast and reliable result has been reached by using COPRAS in the model (Das et al. 2012).

In this study, both the orientation and the interview results were utilized to obtain the data. The most beneficial aspect of the orientation is that the decision maker has the opportunity to observe the personnel. Therefore, it is believed that considering the data from orientation and interview processes provides more effective results.

To identify the most appropriate alternative for occupational safety specialist, a priority value was determined for each alternative and the candidate with the highest priority was selected. The results showed that the most appropriate occupational safety specialist for the X Mutual Health and Safety Unit is the second alternative.

This study presents a model that companies can easily understand and apply to select the most well-suited occupational safety specialist candidate. Apart from providing an integrated model, this study also provides a set of assessment criteria on a basic level for the position of an occupational safety specialist in the Mutual Health and Safety Unit. Future studies can extend the proposed model with fuzzy set theory or grey theory to solve personnel selection problems and other MCDM problems. Moreover, other MCDM methods which are not included in this study such as MULTIMOORA, WASPAS, EDAS etc. can be used to solve similar problems. An analytic network process can be used to evaluate the relationship between criteria in solving personnel selection problems. 
Additionally, the frequency and severity of the occupational accidents, injuries and illnesses that may occur in different sectors are different from each other. It is considered that the occupational accidents and their results can be prevented at a perceptible level, especially in the workplaces such as mining, construction, heavy metals and chemistry where occupational accidents and their results are intensively experienced (Toptanc1 and Arslan, 2017). The essential point to achieve this issue is seeking specific criteria for each sector in the recruitment process of the occupational safety specialist. For this reason, in the future studies, the inclusion of the criteria and professional knowledge required by sectoral branching within the scope of qualifications sought for the recruitment of occupational safety specialist will be important to identify the candidate who meet the needs of specialist most suitably. The selection of the right personnel to the right positions will become easier and systematic, if the same assessment on the basis of the criteria is conducted in the human resource units of other companies.

\section{References}

Aytaç Adal1, E., Tuş Iş1k, A. (2016). "Air conditioner selection problem with COPRAS and ARAS methods", Manas Journal of Social Studies, Vol.5, No.2, 124-138.

Akın, N.G. (2016). "Personel seçiminde çok kriterli karar verme: Bulanık TOPSIS uygulaması", Journal of Business Research Turk, Vol.8, No.2, 224-254.

Aksakal, E., Dağdeviren, M. (2010). "An integrated approach for personel selection with DEMATEL and ANP methods", J. Fac. Eng. Arch. Gazi Univ, Vol. 25, No. 4, 905-913.

Capaldo, G., Zollo, G. (2001). “Applying fuzzy logic to personel assessment: A case study”, Int J Manage Sci, Vol. 29, No.6, 585-597.

Çelik, M., Kandakoğlu, A., Er, I.D., (2009). "Structuring fuzzy integrated multi-stages evaluation model on academic personnel recruitment in MET institutions", Expert Syst Appl., Vol.36, No.3, 6918-6927.

Dağdeviren, M. (2007). "Personnel selection with fuzzy analytical hierarchy process and an application", J. Fac. Eng. Arch. Gazi Univ., Vol. 22, No. 4, 791-799.

Das, M.C., Sarkar, B., Ray, S. (2012). “A framework to measure relative performance of Indian technical institutions using integrated Fuzzy AHP and COPRAS methodology", Socio-Economic Planning Sciences, Vol.46, No.3, 230-241.

Dursun, M., Karsak, E.E. (2010). “A fuzzy MCDM approach for personnel selection”, Expert Syst Appl., Vol. 37, No.6, 4324-4330.

El-Santawy, M.F., El-Dean, R.A.Z. (2012). “On using VIKOR for ranking personnel problem”, Life Sci J., Vol. 9, No. 4, 1534-1536.

Gargano, M.L., Marose, R.A., Kleeck, L. (1991). "An application of artificial neural networks and genetic algorithms to personnel selection in the financial industry", In: Proceedings of the First International Conference on Artificial Intelligence Applications, 257-262.

Gibney, R., Shang, J. (2007). "Decision making in academia: A case of the dean selection process", Math Comput Model, Vol. 46, No.7-8, 1030-1040. 
Güngör, Z., Serhadlığlu, G., Kesen, S.E. (2009). “A fuzzy AHP approach to personnel selection problem”, Appl Soft Comput, Vol. 9, No.2, 641-646.

İş Güvenliği Uzmanlarının Görev, Yetki, Sorumluluk ve Eğitimleri Hakkında Yönetmelik. (2012). Resmi Gazete, Sayı: 28512, Madde 7-10.

Kabak, M., Burmaoğlu, S., Kazançoğlu, Y. (2012). “A fuzzy hybrid MCDM approach for professional selection”, Expert Syst Appl., Vol. 39, 3516-3525.

Karabašević, D., Stanujkić, D., Urošević, S. (2015). “The MCDM model for personnel selection based on SWARA and ARAS Methods", Management, Vol. 20, No.77, 43-52.

Karsak, E.E. (2000). "A fuzzy multiple objective programming approach for personnel selection”, In: IEEE Int Conf Syst Man Cybern., Vol. 3, 2007-2012.

Klemenis, A., Askounis, D. (2010). "A new TOPSIS-based multi criteria approach to personnel selection", Expert Syst Appl., Vol. 37, No.7, 4999-5008.

Liang, S.L., Wang, M.J. (1994). "Personnel selection using fuzzy MCDM algorithm", Eur J Oper Res., Vol. 78, No. 2, 22-33.

Lin, H.T. (2010). "Personnel selection using analytic network process and fuzzy data envelopment analysis approaches", Comput Ind Eng., Vol. 59, 937-944.

Miller, G.M., Feinzig, S.L. (1993). "Fuzzy sets and personnel selection: Discussion and an application", J Occup Organ Psych., Vol. 66, No.1, 163-169.

Özbek, A., Erol, E. (2017). "Ranking of factoring companies in accordance with ARAS and COPRAS methods". International Journal of Academic Research in Accounting, Finance and Management Sciences, Vol.7, No.2, 105-116.

Saaty, T.L. (1980). The analytic hierarchy process, New York: McGraw-Hill.

Saaty, T.L. (2001). Decision making with dependence and feedback: The analytic network process, $2^{\text {nd }}$ ed. Pittsburgh: RWS Publications.

Toptancı, Ş., Arslan, A. (2017). "İş kazalarını önleme uzmanlığı: Ülkemizde iş güvenliği uzmanı adaylarına verilen eğitimin değerlendirilmesi ve iş güvenliği uzmanlığında sektörel branşlaşmanın önemi”, $2^{\text {nd }}$ International Congress of Occupational Safety and Security, Kocaeli, 08-09 Kasım 2017.

Ulutas, A., Shukla, N., Kiridena, S., Gibson, P. (2016). "A utility-driven approach to supplier evaluation and selection: Empirical validation of an integrated solution framework", International Journal of Production Research, Vol.54, No.5.

Vatansever, K., Öncel, M. (2014). “An implementation of integrated multi-criteria decision making techniques for academic staff recruitment", JMML, Vol.1, No.2, 111-126.

Y1ld1z, A., Deveci, M. (2013). "Based on fuzzy VIKOR approach to personnel selection process", Ege Academic Review, Vol.13, No.4, 427-436.

Zavadskas, E., Kaklauskas, A. (1996). Determination of an efficient contractor by using the new method of multicriteria assessment. In: Langford, D.A., Retik, A. (Eds.), International Symposium for The Organisation and Management of Construction, Shaping Theory and Practice, Managing the Construction Project and Managing Risk. (Vol. 2, pp. 94-104). CIB W/65. E. \& F.N. Spon, London. 